\title{
A Study of Depression among Elderly As Affected By Their Gender and Residential Locale: Age Developmental Analysis
}

\author{
Dr. Dev Ashish ${ }^{1}$, Prof Aradhana Shukla ${ }^{2}$
}

Keywords: Depression, Gender, Residential Locale, Age

The overall depressive disorders occurrence rate in elderly people is estimated to be between $10 \%$ - 20\% based on their cultural background, by the World Health Organization (Rangaswamy Sm (ed), 2001 \& Wig NN.2001).

There have been mental health studies done in India based on the community, which show the occurrence rate of depressive disorders among elderly people is between 10\% - 25\%. (Nandi DN, Ajamany S, Ganguli H, Banerjee G, Boral GC, Ghosh A, et al. 1976., Ramachandran V, Menon sarada M, Arunagiri S. 1982).

There have been various studies showing that elderly people have higher rate of having psychological problems, depression being then most common in geriatric psychiatric disorders. The elderly people living in India experience variety of psychological, social, and physical health problems. As mentioned earlier about depression being most common among geriatric psychiatric disorders, it is due to many depressive factors such as life events that affect psychological status of a person. Also with the growing age, the chances of functional loss and morbidity increase as well. Sir James Sterling had said that you do not heal the old age, you protect it, you promote it, and you extend it. In the world of Seneca it has been said that old age is an incurable disease. These are the basic principles that preventive medicine follows. There would be 2 per 1000 patients in the country needing the psychiatric institutional treatment estimated by the Bhore Committee (Report of Health Survey and Development Committee, New Delhi: Govt. of India, 1946).

Mental illness prevalence rate of 20 per 1000 in the population and 14 per 1000 in the population of rural areas was estimated by the Mental Health Advisory Committee to Government of India

\footnotetext{
${ }^{1}$ Kumaun University S.S.J campus Almora, India

${ }^{2}$ Professor, Kumaun University S.S.J campus Almora, India

*Responding Author

(C) 2016, D Ashish, A Shukla; licensee IJIP. This is an Open Access Research distributed under the terms of the Creative Commons Attribution License (http://creativecommons.org/licenses/by/2.0), which permits unrestricted use, distribution, and reproduction in any Medium, provided the original work is properly cited.
} 


\section{A Study of Depression among Elderly As Affected By Their Gender and Residential Locale: Age Developmental Analysis}

in 1966 (Elnagger MN et al 1976). Once again, depression being most common psychiatric disorder can be major or minor in elderly and it is described by various depressive symptoms (Satcher D. 200). There have been many studies done that pointed toward severe underrecognition and under treatment of depression in elderly people (Lebowitz BD, Pearson JL, Schneider L S, Reynolds C F 3rd, 1997, Meyers BS, Morrison M F, et al. 2000, Maletta G, Mattox K M, Dysken M. Update 2000, \& Nierenberg A A , 2001).

The life expectancy of males and females born in 2011 - 2016 is estimated to be 67 and 69 years, respectively and it is also estimated that the percentage of people over the age of 65 years in the world would be more than double, 6.9\% to 16.4\% (Department of International Economic and Social Affairs, 1985). Between the years 2000 - 2050. Out of 580 million older people, the developing countries contain about $60 \%$ and it is estimated to rise to $70 \%$ by the year 2020 (World Health Organization, 1999). The life expectancy after birth and percentage of elderly people in the population is expected to increase due to improved health care facilities in both developed and developing countries (Kinsella K, Phillips DR. Global Aging, 2005). The households are becoming more nuclear due to urbanization, in the developing countries (Bongaarts J. Household Size and Composition in the Developing World., 2001). Values and life style is changing because of industrialization, urbanization, education and being more exposed to the western life style. It has been suggested by Mason that as urbanization will progress, it will take away the likelihood of family taking care of the elderly and adults and elderly living in the same house (Mason KO, 1992). As the age increases, the elderly people are more prone to long term diseases like musculoskeletal, cardiovascular illness, diabetes, cancer, and mental illness. A study done in Udaipur, Rajasthan reveled that there were $42 \%$ elderly people who had psychosocial problems, among which $21.05 \%$ were males and $27.3 \%$ were females (Rahul Prakesh, SK Choudhary \& Uday Shankar Singh, 2004). Occurrence of mental illness in elderly people was 20.2 per 1000 people, shown by another study done by ICMR17 in 1987 (Collaborative studies on severe mental morbidity). Keeping these studies in consideration this study was planned and aimed to find out the depression among old age people in special reference to kumaun hills Uttrakhand. The objective and hypothesis are given bellow.

\section{Objectives of the Study}

1. To study the impact of chronological age on depression.

2. To study the impact of residential locale on depression.

3. To study the impact of gender on depression.

\section{Hypotheses}

1. Variation in chronological-age would lay its impact on depression of elderly participants.

2. Variation in residential locale would lay its impact on depression of elderly participants.

3. Variation in gender would lay its impact on depression of elderly participants. 


\section{A Study of Depression among Elderly As Affected By Their Gender and Residential Locale: Age Developmental Analysis}

\section{METHODOLOGY}

\section{Sample}

360 male and female elderly participants ranging 50 to 70 years were constitute the sample and they were hailed from city town and village area of Kumaun hills Uttarakhand. They were arranged according to the requirements of three way factorial design with three levels of chronological age (50 to 60 years), (61 to 70 years), and (71 to 80 years). Their types of residential locale were city town and village and two genders are male and female that was 20 participants each.

\section{Used Tool}

A Short Form Geriatric depression scale (GDS) consisting of 15 questions was developed in 1986. Of the 15 items, 10 indicated the presence of depression when answered positively, while the rest (question numbers $1,5,7,11,13$ ) indicated depression when answered negatively. Scores of 0-4 are considered normal, depending on age, education, and complaints; 5-8 indicate mild depression; 9-11 indicate moderate depression; and 12-15 indicate severe depression. Validity and reliability: The GDS was found to have 92\% sensitivity and $89 \%$ specificity when evaluated against diagnostic criteria. In a validation study comparing the Long and Short Forms of the GDS for self-rating of symptoms of depression, both were successful in differentiating depressed from non-depressed adults with a high correlation $(\mathrm{r}=.84, \mathrm{p}<.001)$ (Sheikh \& Yesavage, 1986).

\section{DATA ANALYSIS AND RESULTS}

Obtained data were analyzed by analysis of variance and computed in term of depression as affected by chronological age, residential locale and gender. The obtained results are following.

Table- 1: Mean of means for depression among different groups of elderly people.

\begin{tabular}{|c|c|c|c|c|c|c|c|c|c|}
\hline & \multicolumn{3}{|c|}{ A1 } & \multicolumn{3}{c|}{ A2 } & \multicolumn{3}{c|}{ A3 } \\
\cline { 2 - 11 } & B1 & B2 & B3 & B1 & B2 & B3 & B1 & B2 & B3 \\
\hline C1 & 4 & 3 & 2 & 5 & 4 & 4. & 6 & 5 & 5 \\
\hline C 2 & 4.5 & 4.5 & 3.5 & 6.5 & 5.5 & 4.5 & 8.5 & 6 & 7 \\
\hline
\end{tabular}

Table- 2: Mean and S.D of eight groups on depression

\begin{tabular}{|l|l|l|l|}
\hline Groups & Mean & S.D & N \\
\hline Young elder Ss (A1) & 3.58 & 1.72 & 120 \\
\hline Middle elder Ss (A2) & 4.91 & 1.82 & 120 \\
\hline Old elder Ss (A3) & 6.25 & 1.74 & 120 \\
\hline Residents of city elder S (B1) & 5.75 & 1.80 & 120 \\
\hline Residents of town elder Ss (B2) & 4.66 & 1.62 & 120 \\
\hline Residents of village elder Ss (B3) & 4.30 & 1.86 & 120 \\
\hline Male elder Ss (C1) & 4.22 & 1.68 & 180 \\
\hline Female elder Ss (C2) & 5.61 & 1.84 & 180 \\
\hline
\end{tabular}

(c) The International Journal of Indian Psychology, ISSN 2348-5396 (e)| ISSN: 2349-3429 (p) | 185 
A Study of Depression among Elderly As Affected By Their Gender and Residential Locale: Age Developmental Analysis

Table- 3: AB Summary

\begin{tabular}{|l|l|l|l|}
\hline & A1 & A2 & A3 \\
\hline B1 & 4.2 .5 & 5.75 & 7.25 \\
\hline B2 & 3.75 & 4.75 & 5.50 \\
\hline B3 & 2.75 & 4.25 & 6.00 \\
\hline
\end{tabular}

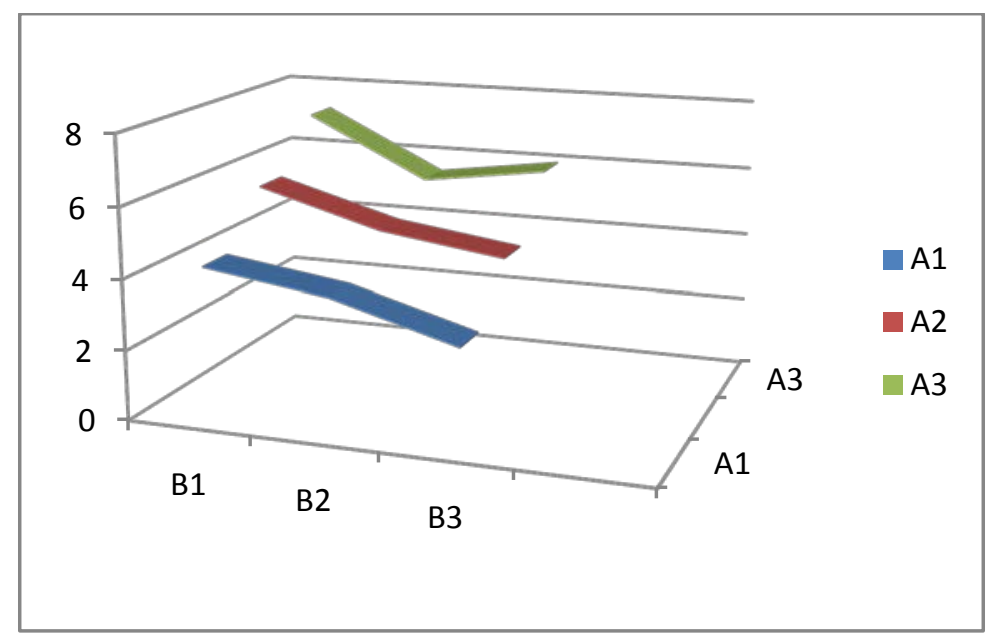

Table- 4: AC Summary

\begin{tabular}{|l|l|l|l|}
\hline & A1 & A2 & A3 \\
\hline C1 & 3.00 & 4.33 & 5.30 \\
\hline C2 & 4.16 & 5.50 & 7.16 \\
\hline
\end{tabular}

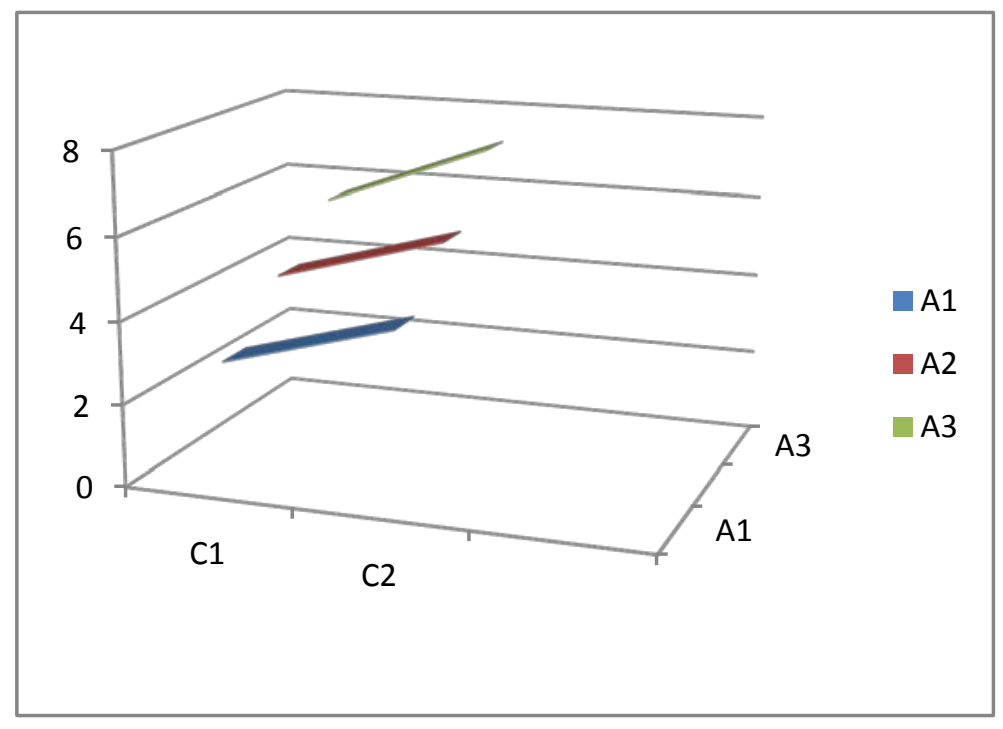

(C) The International Journal of Indian Psychology, ISSN 2348-5396 (e) | ISSN: 2349-3429 (p) | 186 
A Study of Depression among Elderly As Affected By Their Gender and Residential Locale: Age Developmental Analysis

Table- 5: BC Summary

\begin{tabular}{|l|l|l|l|}
\hline & B1 & B2 & B3 \\
\hline C1 & 5.00 & 4.00 & 3.66 \\
\hline C2 & 6.50 & 5.33 & 5.00 \\
\hline
\end{tabular}

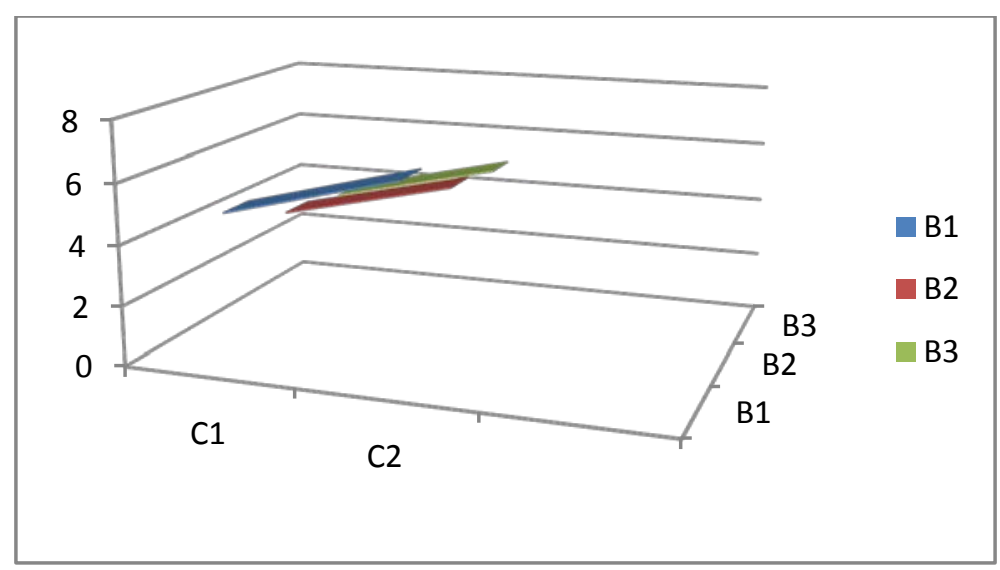

Table- 6: Summary of analysis of variance is showing the impact of chronological age, residential locale and gender on depression.

\begin{tabular}{|l|l|l|l|l|l|}
\hline \multicolumn{1}{|c|}{ Source of variation } & Sum of squares & Df & Mean square & F & $\begin{array}{l}\text { Level of } \\
\text { Significance }\end{array}$ \\
\hline Chronological age $(\mathrm{A})$ & 7.27 & 2 & 3.63 & 4.60 & .05 \\
\hline Residential locale(B) & 5.04 & 2 & 2.52 & 3.19 & .05 \\
\hline Gender $(\mathrm{C})$ & 2.73 & 1 & 2.73 & 3.46 & .05 \\
\hline Interaction $\left(\mathrm{A}^{*} \mathrm{~B}\right)$ & 23.41 & 4 & 5.85 & 7.41 & .01 \\
\hline Interaction $\left(\mathrm{A}^{*} \mathrm{C}\right)$ & 8.20 & 2 & 4.10 & 5.19 & .01 \\
\hline Interaction $\left(\mathrm{B}^{*} \mathrm{C}\right)$ & 7.26 & 2 & 3.63 & 4.60 & .05 \\
\hline Interaction $\left(\mathrm{A}^{*} \mathrm{~B}^{*} \mathrm{C}\right)$ & 21.96 & 4 & 5.49 & 4.60 & .01 \\
\hline Within (Error) & 270.10 & 342 & .79 & 6.96 & \\
\hline
\end{tabular}

Table 6 reveals that F-ratio for the mean effect of chronological age on depression is 4.60. This is statically significant at .05 level of confidence. Finding indicates that the magnitude of depression varied with variation in chronological age. As table 2 depicts that the mean score of young elder subjects on depression is 3.58 , middle elders subjects on depression is 4.91 and old elder subjects on depression is 6.25. This result was apparent that old elder subjects were found most depressed as compared to middle elders subjects and young elder subjects.

Table 6 further reveals that F-ratio for the mean effect of residential locale on depression is 3.19. This is statically significant at .05 level of confidence. Finding indicates that the magnitude of depression varied with variation in residential locale. As table 2 depicts that the mean score of residents of city's subjects on depression is 5.75, residents of town's subjects on depression is 4.22 and residents of village's subjects on depression is 4.3. This result was apparent that

(c) The International Journal of Indian Psychology, ISSN 2348-5396 (e)| ISSN: 2349-3429 (p) | 187 


\section{A Study of Depression among Elderly As Affected By Their Gender and Residential Locale: Age Developmental Analysis}

residents of city's subjects were found most depressed followed by the residents of town and village.

Table 6 further reveals that F-ratio for the mean effect of gender on depression is 3.46. This is statistically significant at .05 level of confidence. Finding indicates that female subjects were high on depression than male participants. As table 2 depicts that the mean score of male subjects on depression is 4.22 and female subjects on depression are 5.61. This result indicates that female subjects were more depressed than male participants.

The F-ratio for the two way interaction between chronological age and gender is 5.19. This is statistically significant at .01 level of confidence. It means that chronological age and residential locale interact in a significant way to influence depression.

The F-ratio for the two way interaction between chronological age and residential locale is 23.41. This is statistically significant at .01 level of confidence. It means that chronological age and residential locale interact in a significant way to influence depression.

The F-ratio for the two way interaction between residential locale and gender is 4.60 . This is statistically significant at .05 level of confidence. It means that residential locale and gender interact in a significant way to influence depression.

The F-ratio for the three way interaction among chronological age, residential locale and gender is 6.95. This is statistically significant at .01 level of confidence. It means that chronological age, residential locale and gender interact in a significant way to influence depression.

\section{INTERPRETATION AND DISCUSSION}

The first hypothesis stated that variation in chronological-age would lay its impact on depression of elderly participants has been accepted. The mean score of young elder subjects on depression are 3.58, middle elder subjects on depression are 4.91 and old elder subjects on depression are 6.25. It showed that the magnitude of depression varied with variation with variation in chronological age. Because the main causes of depression are isolation, alienation, loneliness, detachment boredom, and decline in physical and mental strength etc. When an individual comes to an old age he finds himself more isolated and alienated from the society, the degree of these factors increases with age. The more you get older the more you get isolated and alienated from society because increasing age results in the decline of physical and mental capabilities. So, family and society wants them to free from their all type of responsibilities weather it is familiar or social. Because of it old people get free from these responsibilities due to self acceptance or pressure of society. One hand, this age offers a life free from responsibilities, whereas on the 


\section{A Study of Depression among Elderly As Affected By Their Gender and Residential Locale: Age Developmental Analysis}

other hand, this age also brings with it the negative factors like loneliness and boredom. May be, this is the reason of increased depression found in older people with their increase in their age.

The second hypothesis stated that variation in residential locale would lay its impact on depression of elderly participants has been accepted. The mean score of residents of city's elder subjects on depression are 5.75, residents of town's elder subjects on depression are 4.66 and residents of village's elder subjects on depression are 4.3. It showed that the magnitude of depression varied with variation with residential locale. Life in cities is full activities. Time runs very fast therefore family members do not get time for old members. Besides this, in cities elder people do not get such atmosphere to interact with their neighbors. Due to such circumstances elder living in cities have more negative factors in their life like loneliness, boredom etc. May be, these are the reason that residents of city elders were most depressed participants among residents of town and village participants. Similarly town life is less busy and hectic in comparison to cities. Here time goes slowly, in comparison to cities. People have more time to interact with old family members. And elders are free to interact with people in their surroundings. Perhaps it causes less amount of depression in residents of town elders in comparison to residents of cities elders. When we talk about elder people were living in villages. We found they have a completely different life style. In villages, time runs even more slowly therefore family remembers get sufficient time to interact with elders members. In rural social structure, it is found that older people get more reasons to interact with each other. Due to these positive factors elders of village were found very less depressed in comparison to residents to cities and town's elders.

The third hypothesis stated that variation in gender would lay its impact on depression of elderly participants has been accepted. The mean score of male elder subjects on depression are 4.22, and female elder subjects on depression are 5.61. It showed that the magnitude of depression varied with variation in gender. Because Indian society is basically based on patriarchal and feudal values society have double slandered for males and females. On one hand, society is very harsh, strict and judgmental for women and whereas on other hand society is liberal and flexible for men. That is why; this unjust social system at the end increases the frustration, tension, hopelessness like factors in the life of females. May be these factors causes women elders found more depressed then male elders.

\section{Acknowledgments}

The author appreciates all those who participated in the study and helped to facilitate the research process.

\section{Conflict of Interests}

The author declared no conflict of interests. 


\section{A Study of Depression among Elderly As Affected By Their Gender and Residential Locale: Age Developmental Analysis}

\section{REFRERENCES}

Bongaarts J. Household Size and Composition in the Developing World. New York: Population Council, 2001.

Collaborative studies on severe mental morbidity, ICMR and Dept of Science and Technology, New Delhi: DST, 1987: 52.

Delhi: Govt of India, 1946: 73.

Department of International Economic and Social Affairs: Periodical on Ageing. Volume 1. New York: United Nations, 1985.

Elnaggar MN, Moitra P, Rao MN. Mental Health in an Indian rural community. British J Psych 1974; 46: 327-59.

Govt of India. Report of Health Survey and Development Committee (Bhore Comittee), vol III, Appendix. New

Kinsella K, Phillips DR. Global Aging: the Challenge of Success. Population Bulletin 2005; 60 (1).

Lebowitz BD, Pearson JL, Schneider LS, Reynolds CF 3rd, Alexopoulos GS, Bruce ML, Conwell Y, Katz IR, Meyers BS, Morrison MF, et al. Diagnosis and treatment of depression in late life- Consensus statement update. JAMA 1997; 278 (14):1186-1190.

Maletta G, Mattox KM, Dysken M. Update 2000-Guidelines for prescribing psychoactive drugs. Geriatrics 2000; 55 (3): 65-72, 75-66, 79.

Mason KO. Family change and support of the elderly in Asia: what do we know? Asia Pac Popul J 1992; 7(3):13-32.

Nandi DN, Ajamany S, Ganguli H, Banerjee G, Boral GC, Ghosh A, et al. (1976). The incidence of mental disorders in one year in a rural community in West Bengal. Indian Journal of psychiatry, 18: 79-87.

Nierenberg AA. Current perspectives on the diagnosis and treatment of major depressive disorder. Am J Manag Care 2001; 7 (11 Suppl): S3, 53-366.

Rahul Prakesh, SK Choudhary, Uday Shankar Singh. A Study of Morbidity Pattern Among geriatric Population in an Urban Area of Udaipur Rajasthan. Indian Journal of Community Medicine 3004; 29 (1).

Ramachandran V, Menon sarada M, Arunagiri S. (1982). Soicio-cultural factors in late onset Depression. Indian Journal of Psychiatry. 24(3), 268-73.

Rangaswamy Sm (ed)2001. World health Report: Mental Health : new understanding New Hope. The world health Organization; Geneva, Switzerland.

Satcher D. Mental health- A report of the Surgeon General. 2000; 31: 15-23.

Venkoba Rao A. Psychiatry of old age in India. International Review of Psychiatry 1993; 5:165-170.

Wig NN. (2001). World Health day, 2001. Indian journal of Psychiatry. 43(1): 1-4.

World Health Organization: Ageing - Exploding the Myths. Geneva: Ageing and Health Programme (AHE), 1999.

How to cite this article: D Ashish, A Shukla (2016), A Study of Depression among Elderly As Affected By Their Gender and Residential Locale: Age Developmental Analysis, International Journal of Indian Psychology, Volume 3, Issue 4, No. 65, ISSN 2348-5396 (e), ISSN:2349-3429 (p), DIP:18.01.151/20160304, ISBN: 978-1-365-34680-4 